\title{
Morcegos da Fazenda Monte Alegre, Telêmaco Borba, Paraná (Mammalia, Chiroptera)
}

\author{
Nélio R. dos Reis ${ }^{1}$ \\ Adriano L. Peracchi ${ }^{2}$ \\ Margareth L. Sekiama ${ }^{1}$
}

\begin{abstract}
Bats from Monte Alegre Farm, Telêmaco Borba, Paraná (Mammalia, Chiroptera). A survey of bats species from Monte Alegre Farm is presented. One hundred and two bats of 14 species belonging to Phyllostomidae and Vespertilionidae were colected. Remarks about reproduction and feeding habits are included.

KEY WORDS. Bats, reproduction, feeding habits
\end{abstract}

A área florestal da Klabin Fabricadora de Papel e Celulose S. A., empresa localizada no estado do Paraná, foi criada em 1941, com a finalidade de suprir as necessidades de madeira da fábrica instalada em Monte Alegre, município de Telêmaco Borba. Além de explorar o "pinheiro do Paraná" [Araucaria angustifolia (Bert.) Kuntze] nativo e abundante na região, a empresa empenhou-se, desde o início, na pesquisa de espécies que pudessem se aclimatar na área, bem como preocupou-se com a biodiversidade local. Para tanto, implantou o Parque Ecológico da Fazenda Monte Alegre, visando a realização de estudos científicos nos diversos ecossistemas presentes na região, com especial ênfase no que se refere à fauna e à flora nativas.

Considerando a inexistência de informações sobre os morcegos do Parque, trabalhos de campo foram conduzidos na região, possibilitando um levantamento preliminar das espécies de quirópteros que ocorrem na área, bem como a obtenção de dados bionômicos a respeito.

\section{MATERIAL E MÉTODOS}

\section{Área de estudo}

A Fazenda Monte Alegre conta com área de 126.373,10 hectares e suas coordenadas geográficas são $24^{\circ} 12^{\prime} 42^{\prime \prime} \mathrm{S}$ e $50^{\circ} 33^{\prime} 26^{\prime \prime} \mathrm{W}$. Sua altitude média é de $885 \mathrm{~m}$ e o clima, segundo a classificação de Köppen, enquadra-se como subtropical, com a temperatura média do mês mais frio de $16,3^{\circ} \mathrm{C}$ e temperatura média do mês mais quente $23,2^{\circ} \mathrm{C}$. A média anual de precipitação pluviométrica é de $1.478 \mathrm{~mm}$.

1) Departamento de Biologia Animal e Vegetal, Fundação Universidade Estadual de Londrina. Caixa Postal 6001, 80051-970 Londrina, Paraná, Brasil.

2) Instituto de Biologia, Universidade Federal Rural do Rio de Janeiro. Caixa Postal 74503 , 23851-970 Seropédica, Rio de Janeiro, Brasil. Bolsista do CNPq. 
O Parque Ecológico ocupa uma área de 11.116 hectares, dos quais 7.883 hectares são representados por florestas naturais, algumas delas ainda em estado primitivo. A parte de floresta primária é constituída de árvores altas, destacando-se excepcionais exemplares de Araucaria angustifolia (pinheiro), Patagonula americana L. ("guajuvira") e Eugenia involucrata DC ("cerejeira"). O sub-bosque é dominado por samambaias, bromélias, cipós e avencas.

\section{Métodologia}

Os trabalhos de campo foram realizados no período de maio de 1992 a novembro de 1994, procurando-se tanto quanto possível amostrar as quatro estações climáticas e, para isso, foram empregadas redes japonesas (mist nets) armadas nas bordas ou no interior da mata. Os exemplares capturados foram mantidos em sacos de pano por tempo suficiente para o recolhimento de fezes que, posteriormente, no laboratório, foram desmanchadas em placas de Petri com água, sendo então procuradas sementes, fragmentos de insetos ou outros resíduos indicadores dos hábitos alimentares das espécies colecionadas.

As coletas proporcionaram a captura de 102 quirópteros, liberados, em sua maioria, após a identificação e anotações pertinentes, tendo sido sacrificados apenas alguns exemplares de cada espécie colecionada, visando a representação sinóptica da quiropterofauna da região. Os exemplares sacrificados foram fixados em formol $10 \%$ e conservados em álcool $70^{\circ} \mathrm{GL}$, tendo sido incorporados à coleção do Departamento de Biologia Animal e Vegetal da Universidade Estadual de Londrina.

Nas citações das espécies colecionadas adotamos a nomenclatura apresentada por KOOPMAN (1993) e a ordem sistemática proposta por CABRERA (1958).

\section{RESULTADOS}

\section{Phyllostomidae Micronycteris Gray, 1866}

\section{Micronycteris megalotis (Gray, 1842)}

Dois exemplares foram colecionados e em suas fezes foram encontradas sementes de Ficus sp. e fragmentos de insetos. Esses exemplares foram capturados na primavera, em área recoberta por capoeira, aproximadamente às 20 horas.

Material examinado. Dois exemplares não sexados, 12-XI-1992.

\section{Chrotopterus Peters, 1865}

\section{Chrotopterus auritus (Peters, 1856)}

Quatro exemplares dessa espécie carnívora foram coletados. Um macho foi capturado no outono, aproximadamente às 20 horas. Duas fêmeas foram coletadas no inverno, uma às 18,45 horas e a outra às 20 horas e uma terceira foi obtida na primavera às 18,30 horas. Todos esses exemplares foram encontrados em área de floresta.

Material examinado. Quatro exemplares: 1 macho 24-V-1992, 2 fêmeas 3-IX-1994, 1 fềmea 22-XI-1994. 


\section{Mimon Gray, 1847}

\section{Mimon bennetti (Gray, 1838)}

Uma fêmea não grávida dessa espécie pouco freqüente foi colecionada no outono e as suas fezes continham fragmentos de insetos.

Material examinado. Um exemplar: 1 fêmea 24-V-1992.

\section{Anoura Gray, 1838}

\section{Anoura caudifer (E. Geoffroy, 1818)}

Três exemplares dessa espécie polinívora foram colecionados no inverno, sendo um macho com testículos escrotados e duas fêmeas. Nas fezes do primeiro exemplar foram encontrados fragmentos de coleópteros e grãos de pólen.

Material examinado. Três exemplares: 1 macho e 2 fềmeas 17-IX-1992.

\section{Carollia Gray, 1838}

\section{Carollia perspicillata (Linnaeus, 1758)}

Quatro exemplares dessa espécie frugívora foram obtidos: um macho colecionado no inverno, apresentou sementes de Piper spp. nas fezes e de três fêmeas capturadas na primavera, duas eram lactantes. Uma dessas fêmeas eliminou sementes de Solanum sp. nas fezes, enquanto as outras duas defecaram sementes de Piper spp..

Material examinado. Quatro exemplares: 1 macho 17-IX-1992, 1 fêmea 22-XI-1994, 2 fêmeas 23-XI-1994.

\section{Sturnira Gray, 1842}

\section{Sturnira lilium (E. Geoffroy, 1810)}

Nove exemplares dessa espécie frugívora foram obtidos, dos quais quatro apresentavam sementes de Solanum spp. nas fezes, enquanto outro espécimen eliminou sementes de Myrtaceae não identificada. Duas fêmeas e um macho juvenis foram colecionados no mês de maio, bem como um macho com testículos escrotados.

Material examinado. Nove exemplares: 2 fêmeas e 1 macho 23-V-1992, 1 macho e 1 indivíduo não sexado 24-V-1992, 1 macho 7-VIII-1992, 1 fêmea 18-IX-1992, 1 indivíduo não sexado IV-1994, 1 macho 22-XI-1994.

\section{Artibeus Leach, 1821}

\section{Artibeus lituratus (Olfers, 1818)}

Quarenta e três exemplares dessa espécie comum de morcego frugívoro foram obtidos. De 12 fêmeas colecionadas no outono, uma era lactante, uma estava grávida e sete eram juvenis e de 13 machos capturados, um apresentava testículos escrotados e oito eram juvenis. Uma das fêmeas colecionadas eliminou sementes de Solanaceae não determinada. Duas fềmeas obtidas no inverno estavam grávidas, 
enquanto que sete fêmeas capturadas na primavera eram lactantes. De cinco machos colecionados na primavera quatro apresentavam testículos escrotados. De 12 exemplares capturados naquela estação, quatro eliminaram nas fezes sementes de Cecropia sp., três, sementes de Ficus spp. e um, sementes de Solanum spp.. Esses dados confirmam observações semelhantes realizadas em outras regiões (REIS et al. 1993, 1996).

Material examinado. Quarenta e três exemplares: 7 machos e 9 fêmeas 23-V-1992, 3 fêmeas e 6 machos 24-V-1992, 1 macho e 2 fêmeas 17-IX-1992, 1 macho 18-IX-1992, 2 indivíduos não sexados IV-1993, 7 fêmeas 22-XI-1994, 5 machos 23-XI-1994.

\section{Artibeus obscurus (Schinz, 1821)}

Um macho e uma fêmea desse morcego frugívoro pouco freqüente na região foram obtidos na primavera de 1994. A fêmea era lactante e nas fezes do macho foram encontradas sementes de Cecropia spp..

Material examinado. Dois exemplares 1 macho e 1 fêmea 22-XI-1994.

\section{Desmodus Wied, 1826}

\section{Desmodus rotundus (E. Geoffroy, 1810)}

Três exemplares dessa espécie hematófaga foram colecionados na primavera.

Material examinado. Três exemplares: 2 indivíduos não sexados 12-XI1992, 1 fêmea 22-XI-1994.

\section{Vespertilionidae}

Myotis Kaup, 1829

\section{Myotis nigricans (Schinz, 1821)}

Dezesseis exemplares desse morcego insetívoro foram capturados. Dois exemplares obtidos no outono eliminaram fragmentos de insetos não identificados nas fezes, o mesmo ocorrendo com outro indivíduo colecionado na primavera. De 11 exemplares colecionados no inverno, quatro eliminaram nas fezes fragmentos de insetos não identificados, mas um macho obtido em agosto eliminou fragmentos de Diptera e Lepidoptera, enquanto uma fêmea capturada na mesma ocasião, defecou fragmentos de Diptera. Um macho obtido em setembro defecou fragmentos de Coleoptera e duas fêmeas eliminaram fragmentos de Diptera e Coleoptera. Um macho colecionado na primavera apresentava testículos escrotados.

Material examinado. Dezesseis exemplares: 1 fêmea 24-V-1992, 1 macho e 1 fêmea 7-VIII-1992, 1 macho e 2 fêmeas 17-IX-1992, 1 macho 18-IX-1992, 1 indivíduo não sexado 12-XI-1992, 1 macho 10-IX-1993, 1 fêmea e 1 indivíduo não sexado V-1994, 3 machos e 1 fêmea 3-IX-1994, 1 macho 22-XI-1994.

\section{Myotis rubra (E. Geoffroy, 1806)}

Adotamos a correção proposta por WoODMAN (1993) para o nome científico desse morcego insetívoro. 
Cinco exemplares desse quiróptero foram capturados com rede de espera. Um deles, obtido no inverno, apresentou fragmentos de Diptera e Coleoptera nas fezes, enquanto três outros, capturados na mesma estação ou no outono, apresentaram fragmentos de insetos que não puderam ser identificados.

Material examinado: 5 exemplares: 1 macho 23-V-1992, 1 fêmea 17-IX1992, 1 indivíduo não sexado IV-1994, 1 macho e 1 fêmea 3-IX-1994.

\section{Eptesicus Rafinesque, 1820}

\section{Eptesicus brasiliensis (Desmarest, 1819)}

Um único exemplar dessa espécie foi capturado em setembro, era um macho e não apresentava testículos escrotados.

Material examinado. Um exemplar: 1 macho 10-IX-1993.

\section{Eptesicus diminutus Osgood, 1915}

Um macho que não apresentava testículos escrotados foi capturado no outono. Outros quatro machos dessa espécie insetívora, que também não apresentavam testículos escrotados foram colecionados no inverno. Nas fezes desses últimos exemplares foram encontrados fragmentos de Lepidoptera e Diptera.

Material examinado: 5 exemplares: 1 macho 23-V-1992, 4 machos 7-VIII1992.

\section{Histiotus Gervais, 1856}

\section{Histiotus velatus (I. Geoffroy, 1824)}

Dois exemplares foram capturados com redes no inverno. Uma colônia desse morcego insetívoro, com aproximadamente 65 indivíduos se abrigava, no outono, no forro de uma casa de madeira, localizada em pequeno povoado existente no Parque e nessa ocasião foram colecionados dois exemplares.

Material examinado. Quatro exemplares: 2 machos 20-V-1993, 2 indivíduos não sexados 2-IX-1994.

\section{REFERÊNCIAS BIBLIOGRÁFICAS}

Cabrera, A. 1958. Catálogo de los mamíferos de América del Sur. Rev. Mus. Argent. Cienc. Nat., Zool., 4 (1): XVI+307.

Koopman, K.F. 1993. Order Chiroptera, p.137-241. In: D.E. WiLson \& D.M. REEDER (Eds). Mammal species of the world. A taxonomic and geographic reference. Washington D.C., Smithsonian Institution Press, $2^{\text {nd }}$ ed., XVIII+1206p.

ReIs, N.R.; A.L. PERACCHI \& M.K. OnUKI. 1993. Quirópteros de Londrina, Paraná, Brasil (Mammalia, Chiroptera). Revta bras. Zool. 10 (3): 371-381.

ReIs, N.R.; A.L. Peracchi; M.F. MÜller; E.A. Bastos \& E.S. SoARES. 1996. Quirópteros do Parque Estadual Morro do Diabo, São Paulo, Brasil. (Mammalia, Chiroptera). Rev. Brasil. Biol. 56 (1): 87-92.

WOODMAN, N. 1993. The correct gender of mammalian generic names ending in -otis. Jour. Mammal. 74 (3): 544-546.

Recebido em 29.VIII.1997; aceito em 12.IV.1999. 